\title{
Cath lab to the rescue. Now with room to grow!
}

\author{
Carl L. Backer, MD, a,b and Jeffrey G. Gossett, $\mathrm{MD}^{\mathrm{c}, \mathrm{d}}$
}

\footnotetext{
From the Divisions of a Cardiovascular-Thoracic Surgery and 'Cardiology, Ann \& Robert H. Lurie Children's Hospital of Chicago; and the Departments of ${ }^{b}$ Surgery and ${ }^{\mathrm{d}}$ Pediatrics, Northwestern University Feinberg School of Medicine, Chicago, Ill.

Disclosures: Authors have nothing to disclose with regard to commercial support.

Received for publication July 27, 2016; accepted for publication July 29, 2016; available ahead of print Sept 17, 2016.

Address for reprints: Carl L. Backer, MD, Division of Cardiovascular-Thoracic Surgery, Ann \& Robert H. Lurie Children's Hospital of Chicago, 225 E Chicago Ave, MC 22, Chicago, IL 60611 (E-mail: cbacker@ luriechildrens.org).

J Thorac Cardiovasc Surg 2016;152:e113

$0022-5223 / \$ 36.00$

Copyright (C) 2016 by The American Association for Thoracic Surgery

http://dx.doi.org/10.1016/j.jtcvs.2016.07.062
}

Heal and colleagues have reported the successful treatment of an 8-year-old girl who developed a traumatic aortic pseudoaneurysm. ${ }^{1}$ This type of injury was previously treated with a thoracotomy and resection of the pseudoaneurysm, often using partial cardiopulmonary bypass. Instead, Heal and colleagues treated their patient in the cardiac catheterization lab with a balloon-expandable covered stent. The covered stent that was placed may be re-dilated to allow expansion to a maximum diameter of $24 \mathrm{~mm}$. This child is now protected from pseudoaneurysm rupture and may need no further surgical intervention. Although, as the authors note, this procedure has been previously reported, ${ }^{2}$ to our knowledge this is the youngest patient to undergo successful stent implantation for a traumatic aortic pseudoaneurysm. This is a rare occurrence in a child and it is of importance to all physicians who may potentially care for this type of patient.

This case report is notable for several important reasons. First, the group at the Medical University of South Carolina demonstrated an excellent example of collaboration between multiple services. The child was cared for by the pediatric trauma service, cardiologists, neurosurgeons, and medical imaging. Her case was complicated by a hemorrhagic brain contusion and subdural hematoma. Avoiding cardiopulmonary bypass and heparinization in this patient was relatively important.

Second, the authors demonstrated outstanding use of 3-dimensional computed tomography imaging. The computed tomography angiograms very clearly show the 3 -dimensional anatomy of the pseudoaneurysm. The location is classic, just distal to the insertion of the ligamentum. The high-speed collision resulted in a fracture of the aorta, which is anchored by the ligamentum. The beautiful, 3dimensional image gave interventional cardiologists a precise roadmap for placement of a covered stent.

Third, the technology of stents and implanted devices continues to improve and increases the number of indications for the devices. The currently available selfexpanding endovascular grafts are limited by requiring a

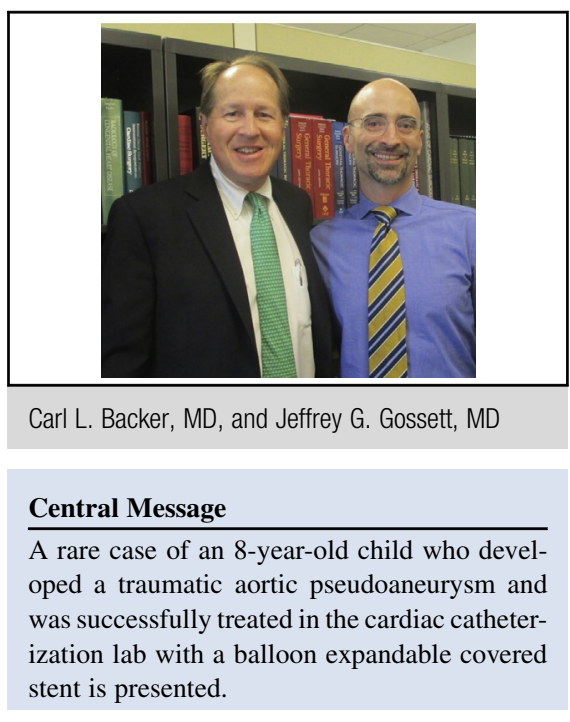

See Article page e109.

very large arterial sheath and they cannot be dilated later to a larger diameter. The balloon-expandable covered stent used in this case circumvents both of those issues. These stents have been studied extensively in the setting of coarctation of the aorta. ${ }^{3}$ They have recently received Food and Drug Administration approval and should now be widely available in congenital laboratories. The postoperative angiogram shows a beautiful result with essentially normal flow through the descending thoracic aorta and no residual pseudoaneurysm. The covered stent can be re-expanded to a maximum diameter of $24 \mathrm{~mm}$, meaning that this child should require no future surgical intervention. The previous generation of materials would have required resection of the stent because the child would have undoubtedly developed a neocoarctation with growth.

Congratulations to the group at the Medical University of South Carolina for this outstanding result. The strategy described is now in the armamentarium of clinicians caring for children with the rare condition of traumatic aortic pseudoaneurysm.

\section{References}

1. Heal ME, Chowdhury SM, Bandisode VM. Balloon-expandable covered stent im plantation for treatment of traumatic aortic pseudoaneurysm in a pediatric patient. J Thorac Cardiovasc Surg. 2016;152:e109-11.

2. Goldstein BH, Hirsch R, Zussman ME, Vincent JA, Torres AJ, Coulson J, et al Percutaneous balloon-expandable covered stent implantation for treatment of traumatic aortic injury in children and adolescents. Am J Cardiol. 2012;110:1541-5.

3. Meadows J, Minahan M, McElhinney DB, McEnaney K, Ringel R, COAST Inves tigators. Intermediate outcomes in the prospective, multicenter Coarctation of the Aorta Stent Trial (COAST). Circulation. 2015;131:1656-64. 